\title{
Innovation measures through the European project SERKET
}

\author{
B. Monnier \& F.-X. Josset \\ THALES Research \& Technology, Palaiseau, France
}

\begin{abstract}
Innovation has become a very common word. All companies need innovation to make their business grow and to increase their profits. A lot of people, academic institutes and companies are trying to find a solution to the main problem in the innovation field: "how to evaluate innovation?"

This paper addresses this main issue and suggests a method to measure the innovation level of a product or a service, based on Monnier's Innovation Matrix (C) (Monnier's Innovation Matrix: copyright $(20042007$ Bernard MONNIER. ALL RIGHTS RESERVED. This concept is not to be reproduced, modified, adapted, published, translated in any material form in whole or in part nor disclosed to any third party without the prior written permission of Bernard Monnier) (MIM(C).

The SERKET study is the first European project that addresses this topic. Its Work Breakdown Structure includes the development of this new tool in order to evaluate the outputs of the project; the main objective is to bring those outputs quickly to the market.
\end{abstract}

Keywords: innovation, Monnier's Innovation Matrix $($, innovation measurement, level of innovation, SERKET.

\section{Introduction to innovation}

Creativity is the production of novel ideas; whereas innovation is the successful exploitation of new ideas. It's about bringing new knowledge and processes into business and/or developing new, high value-added products, processes and services. 
The main issue is to find a way to evaluate the level of innovation. There are no definitive metrics for innovation. Measures of innovative success vary according to companies and industries.

One famous definition of innovation is provided below:

"Innovation has nothing to do with how many $R \& D$ dollars you have... It's not about money. It's about the people you have, how you're led, and how much you get it." (Steve Jobs)

SERKET ("SEcuRity KEeps Threats away”), a EUREKA/ITEA project aimed at developing a novel software infrastructure for public security applications, includes an activity in its WBS focusing on the statement of a new method to measure the innovation level.

\section{A dedicated tool to measure innovation}

The Monnier's Innovation Matrix (C) (Monnier's Innovation Matrix: copyright $\mathrm{C}$ 20042007 Bernard MONNIER. All rights reserved) (MIMC) is a new tool to measure the innovation level of a product (in a general sense). This tool is mainly composed of:

1. A two-dimensional matrix where the " $X$ " axis represents the market level and the "Y" axis the idea, the technical level of the products or services to be evaluated. Many parameters are considered for assessing each axis;

2. Methods for moving from one quadrant to another more favourable one.

This matrix could be considered as a standard measure for different products, similar to a diagnostic framework where you may identify the parameters to be focused on in order to improve the innovation level. This paper describes how this matrix is built.

The MIMC is split into seven areas (see Figure 1), that distributes innovation in seven levels with the following semantics:

- LEVEL 1: There is only a preliminary idea for a business or a product (or service) to be evaluated. The market is not really identified. The solution to the problem is poor and needs to be confirmed. It is the lowest level of innovation

- LEVEL 2: There is a technical idea, a concept, a product or a service to be promoted in a market which is not yet identified

- LEVEL 3: There is an identified market but not a solution to answer this demand

- LEVEL 4: There is a product/service and an identified market for it.

- LEVEL 5: There is a sophisticated product/service and an identified market for it

- LEVEL 6: There is a product/service and a huge identified market for it.

- LEVEL 7: There is a sophisticated product/service and a huge identified market for it; it is the highest level of innovation. 


\section{MONNIER'S INNOVATION MATRIX @}

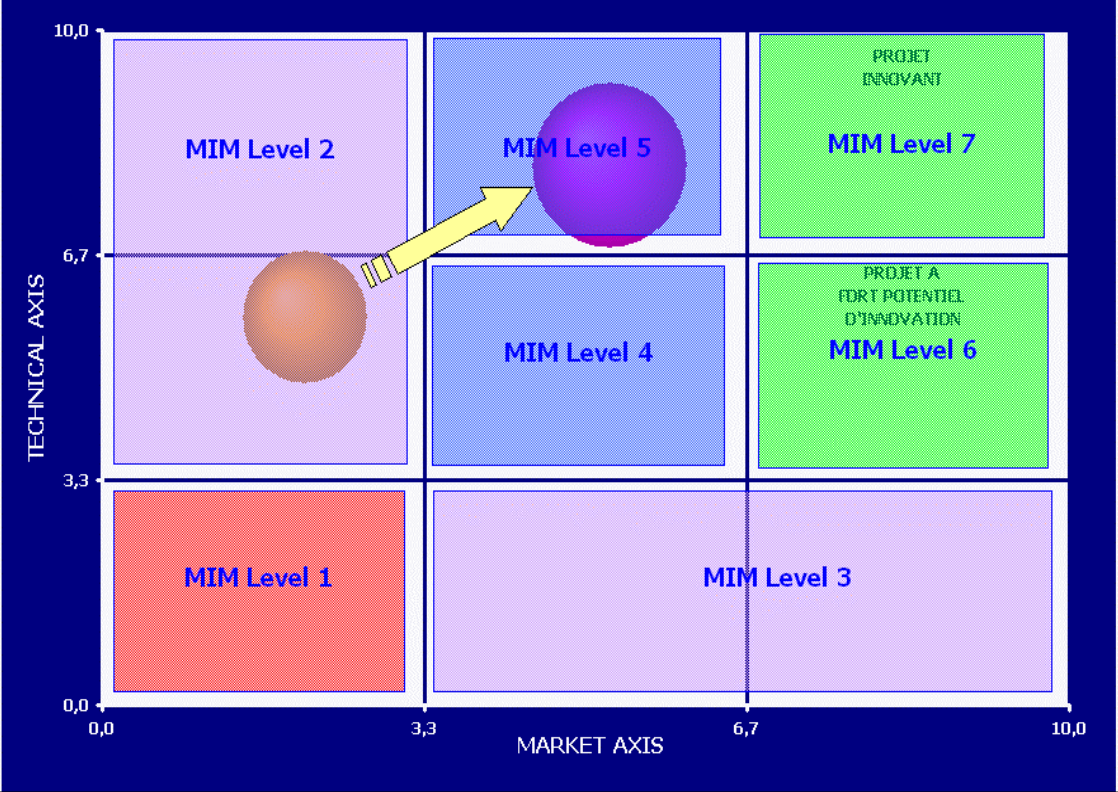

Copyright@ 20042007 Bernard MONNIER. All rights reserved.

Figure 1: $\quad$ Monnier's Innovation Matrix@: level of innovation for products.

The performance of the measure depends on the assessment of the axes; this paper addresses this point. It also depends on the accuracy of the information provided by assessment of each axis.

\section{Example of use on the SERKET project}

SERKET aims at providing not a final product, but the result of a series of studies that materialise into a common demonstrator that may include products (or future products). Such R\&D components and products would definitely gain being evaluated separately. The innovation level of SERKET is assessed after segmentation by activities.

Therefore, applying the innovation measurement concept to our current study, SERKET is divided according to four activities:

- Algorithm: Signal processing (e.g., image processing techniques, audio processing), data fusion (multi-sensor or mono-sensor), information processing (higher-level information fusion, threat assessment, situation awareness technologies)...

- Software architecture: Middleware (e.g., peer-to-peer, client-server), communication protocols, monitoring and control principle... 
- Hardware architecture: Sensors (e.g., cameras, microphones, badge readers, IR barriers, NRBC detectors), dedicated computers (video streaming, data and information processing), storage servers, screens (monitors, larger screens, screen walls), and other types of device...

- System and services: Final application, services, training, and maintenance...

This approach enables more detailed and useful information to promote the final result of the SERKET study.

\section{The assessment of each axis}

The quality of a measure depends on the definition of the axes. The questions asked when one wants to evaluate the market axis are split into four parameters: the market, the competitors, the flexibility and the pro-activity of the organization for promoting the evaluated product. Concerning the idea or technical axis, three parameters are proposed: the technical solution itself, the environment and the protection level (patents).

\subsection{Market axis}

\subsubsection{Market}

The market is evaluated in terms of volume, expected returns, and growth margin. Innovation is also useful for increasing the market share, therefore the expected level of future growth has also to be considered.

The market parameter has to be modulated by the risks of this market and the reliability of the previous "quotation".

\subsubsection{Competitors}

This parameter captures the evaluation of the competitors, their number and the level of their competence. We suggest evaluating the difficulties for a new entrant to win in this market, as well as the level of protection against the new entrants.

We can also include the evaluation of a really new function or process that consists of differentiating the product from those of the competitors.

\subsubsection{Flexibility}

Here we propose to measure the company's organisation relevance, the competence in sales and marketing, and the relevance of the business model proposed for bringing this product to the market. Such measures also depend on whether the product is specific or not, if it is built for a limited domain of application or not.

\subsubsection{Pro-activity}

Here, we want to estimate the capability of the solution to anticipate market needs, does the market exist or not, is it promising, is there a reliable solution, is it validated enough: A series of questions in order to measure the pro-activity degree of the organisation. 


\subsection{Technical axis}

\subsubsection{Technical solutions}

A first set of questions are about the technical solutions: Are they validated enough, what are their reliability and time-to-market?

\subsubsection{Technical environment}

This parameter is used to evaluate the global context of the problem. Is the solution technically difficult to solve, is there internally knowledge to manage a potential new problem. The risk level needs to be assessed, in financial, marketing and technical fields. The respect of environmental conditions could be a risk that needs to be considered.

We also have to evaluate if there are method and tools to enhance creativity, to manage knowledge, to measure the level of innovation, and to monitor recommendations.

\subsubsection{Protection level}

The protection of a technical solution is very important. We need to evaluate if the solution is protected by patents and if this protection is efficient enough to avoid copyright infringement: is it easy to copy and is it easy to detect a copy of the product?

\section{From measurement to strategy}

We propose in this Section one process in four steps that leads towards a global assessment of the degree of innovation of a given product, in as much detail as possible.

The four steps are the following:

- Situation analysis

- Definition of a strategy

- Implementation of the method adopted in accordance with the strategy

- Re-evaluation of the product innovation

\subsection{Analysis of the situation}

Figure 1 shows us that the best quadrants are those on the right, where the level of the market is the highest; this means that a market has been found for the product/service under consideration. We therefore present a method with an associated tool to implement a move from one position to another that is more favourable. Usually in organisations, senior management has to be met in order to assess the current position and to decide if we really need to move from one quadrant to a more favourable one.

\subsection{Defining a strategy}

A detailed analysis of each criterion on each axis could help to define a strategy for the move. Generally, the only movement we wish to increase is along the 
market axis; that means to move from the left to the right side. But sometimes, if we expect to reach a high level of market share, we also need to move up from a lower to a higher quadrant. For this reason, Monnier has provided methods for both movements in the matrix [10].

\subsection{Implementation of methods}

After defining the best strategy, it is necessary to manage the implementation of the method described above.

\subsection{Re-evaluation of the modified product/service}

At the end of the process, the product or service should be quite different from the initial one. The modification shall imply a move to a better quadrant (see Figure 2). The goal of this phase is only to confirm that the expected position in the matrix has been reached (otherwise, the cycle needs to be executed once more).

Monnier's Innovation Matrix @

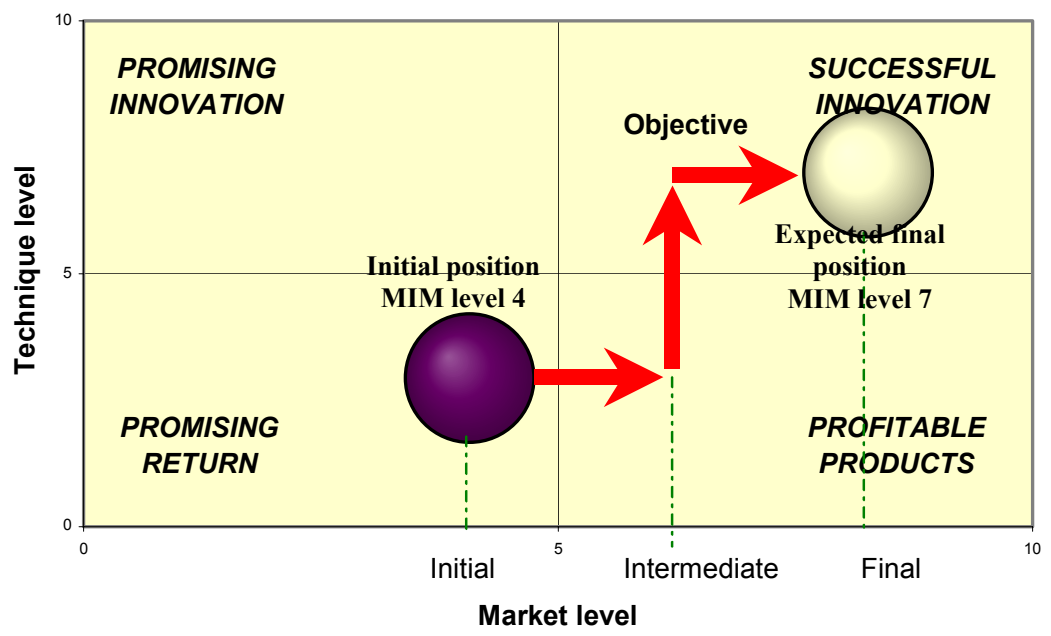

Figure 2: $\quad$ Monnier's Innovation Matrix@ : a strategic tool.

\section{Conclusion}

Innovation is defined as a successful development and exploitation of a new idea. It is a powerful generator for the achievement of improved business performance in highly competitive and changing markets. Innovation is responsible for increased market share, a higher growth rate and greater profitability. Innovation applies to new technologies, products and processes, as 
well as the adoption of best practices in industry. Monnier's Innovation Matrix (C) with the associated methods could be efficient to measure innovation and to define a strategy for increasing it. The action plan for improving our current position may be followed using the same tool.

SERKET is the first European project where such a method and tools are being deployed. The innovation measure of each part of the project will be useful for the dissemination plan. If improvement is needed, the same tool could be used.

The evaluation process is currently being achieved with the valuable support of the SERKET consortium; the authors will publish a synthesis of the results soon.

It will be of prime interest to point out the global innovation status of the project's major findings, that is a software system supporting the security officers in public places and for large events. In addition, the synthesised results on each one of the four parts - algorithms, software architecture, hardware architecture, and system and services - will help in identifying current technological shortcomings with respect to the growing market of global security. This information will then be very valuable for SERKET member countries in evaluating what needs to be done going forward security needs.

\section{References}

[1] Christensen C. M. (2003). The Innovator's Dilemma: The Revolutionary Book That Will Change the Way You Do Business. Harper Collins edition.

[2] Christensen C. M. (1997). The Innovator's Solution: Creating and Sustaining Successful Growth. Hardcover edition.

[3] Millier P., \& Palmer R. (2000). Nuts, Bolts \& Magnetrons: A Practical Guide for Industrial Marketers. Wiley edition.

[4] Millier P. (2004). L'Etude des Marchés qui n'Existent pas Encore. Edition d'Organisation.

[5] Monnier B. (2004, Nov 3-5). "Application of the TRIZ method to business management activities". TRIZ Future 2004, Florence, Italy.

[6] Monnier B. (2005, March 20-23). "A new tool to evaluate supplier's level of innovation". IPSERA International Conference, Archamps, France.

[7] Monnier B. (2005, April 2-5). "A New Process For Innovation Improvement”, SAM International Conference, Las Vegas, USA.

[8] Monnier B. (2006, April 6-8). "Supplier's Innovation Management by Portfolio Model", $15^{\text {th }}$ IPSERA International Conference, San Diego, USA.

[9] Monnier B. (2006, September 4-7). "Innovation Improvement Strategy Using TRIZ", 1 st AMETRIZ International Conference, Puebla, Mexique.

[10] Slocum M., Domb E. (2002). "Software Review: CreaTRIZ 2.2 and CreaTRIZ 2.2 for Business and Management", Retrieved 2004 from Web site: http://www.triz-journal.com/archives.

[11] Tidd J., Bessant J., Pavitt K., (n.d.). Managing Innovator: Integrating Technological, Market and Organizational Change. Wiley edition. 